\title{
Recent Advances in Plasma /Nanoparticles Treatments of Textile Fibers
}

\author{
W. M. Raslan*, H. El- Sayad and A. A. El-Halwagy \\ Textile Industries Research Division, National Research Centre, Cairo 12622, Egypt;
}

\begin{abstract}
A GENERAL review on natural and synthetic fabrics treatments with low-temperature plasma using various gases in presence of different types of nanoparticles is given. The effect of using plasma/nanoparticles on the surface morphology, physical and mechanical properties of the treated fabrics is declared. Using combined plasma and nanoparticles treatments show a noticeable effect and great enhancement on many properties of all textile fibers. Improvement of functional properties of textile materials is considered crucial to the textile industry. Dyeing and printing improvement could be achieved and it was found to depend on the types of plasma and nanoparticles used. Scanning electron microscopy showed that the surface characteristics of all fabrics were changed while the bulk properties were mainly maintained unchanged. Textile industries see a promising future for plasma/ nanoparticles technology, with the environmental and energy conservation benefits, in developing high-performance materials for the world market.
\end{abstract}

Keywords: Plasma, Etching, Wettability, Nanoparticles, UV absorbance, XPS, Textile Fibers.

\section{Introduction}

The textile industry in developed countries is confronting the world's marketing conditions and competitive challenges which are driving towards the development of advanced, highly functional textiles and textiles with higher added value. The textile finishing industry, which is the backbone of the fashion clothing sector, creates the highest volume of waste water compared with other stages in textile manufacturing. The expectations of modern consumers regarding the textile products have increased dramatically; consumers want textiles that suit their taste and are health-friendly. It is now very important for the textile industries to reconsider the technologies and chemicals used, so that they can satisfy environmental and consumer requirements. Enzymes, nature-based finishing agents, nanotechnology and disruptive technologies such as plasma finishing are gradually replacing conventional systems for finishing textile materials ${ }^{(1)}$. Enhancement of functional properties of textile materials is considered crucial to the textile industry. The developments in chemical treatments of textile materials for imparting functional properties will be determined by factors like economic forces, market demands, and environmental concerns. Textile chemicals are required at economical cost at global level, which is achieved by decrease in the quantity of water to be shipped. Generally undesirable side effects are caused by the use of textile chemicals. Products like plasma need less energy and water to perform such functional characteristics ${ }^{(1)}$. Textile industries see a promising future for plasma technology, with the environmental and energy conservation benefits, in developing high-performance materials for the world market ${ }^{(2)}$.

\section{Plasma Treatments}

The plasma state consists of an equal part of negatively and positively charged particles, excited states, radicals, and vacuum ultraviolet (VUV) radiation. Surface treatments of materials can be performed by non-equilibrium plasmas, which are excited by electric fields. The electrons gain energies to excite, dissociate and ionize the atoms and molecules. The reactive plasma particles and radiation yield a Nano-scaled interaction with material surfaces by chain scission and crosslinking reactions, radical formation, etching or deposition. The bulk properties of materials can thus be maintained. Textiles and fibers differ from other materials mainly by their complex structure showing openings at different length scale (micro- to Nano meter range) such 
as filament or inter fiber distances, resulting in higher surface areas ${ }^{(3)}$. Plasma treatment is a fast solvent free technique. The operation procedure is simple and well controlled (4). Today, with increasing awareness of environmental concerns, a significant amount of ecological legislation has been introduced regarding fiber treatment that use huge amount of chemicals and water ${ }^{(5)}$. Laboratory plasma treatment can be proving that it changes the surface, chemical and physical properties of the fibers. Future progress and different techniques are used as a solution for plasma scaling problems ${ }^{\left({ }^{6}\right.}$. Low pressure plasma techniques have been used for textile and polymer surface modification. The low pressure plasma has advantages as like uniform glow, low breakdown voltage, high concentration of reactive species and generation of non-thermal plasma.

\section{Nanoparticles Treatments}

Recently, Nanoparticles (NPs) have attracted a good deal of attention in various areas, including chemistry, physics, materials science, life sciences, and engineering because of their superior characteristics, such as optical, magnetic, electronic and catalytic properties ${ }^{(7)}$. AgNPs is one of the best candidates for several applications including bio sensing, antibacterial, antiviral, antifungal activities, drug delivery, catalysis, electrochemical and conductivity ${ }^{(8,9)}$. Metal nanoparticles are prepared by many physical and chemical techniques, but they are not eco-friendly ${ }^{(10,11)}$. Nano-technology is considered as the futuristic approach for improvement in the performance of textiles ${ }^{(12-16)}$. The major emphasis has been towards use of Nano size substances and generating Nano structures during finishing and manufacturing processes to impart anti-bacterial, water and oil repellency, soil resistance, antistatic, flame retardancy and enhanced dye-ability properties. Silver nanoparticles have anti-bacterial properties on Gram positive as well as Gramnegative bacteria. Nanoparticles were dispersed in the polymer (binder) matrix or coated/impregnated and finally become immobilized in the cotton fiber. The polymeric materials have been found to be suitable to form composite dressings with silver nanoparticles because of their structure, tailor-ability and flexibility. Several techniques have been reported for polymer immobilization in antimicrobial coatings based on their particular characteristics ${ }^{(1)}$.

\section{Plasma/Nanoparticles Treatment}

The use of plasma technology to modify textile surfaces, etching and deposition reactions can be used to obtain Nano-particle or Nano-porous

J. Text. Color. Polym. Sci. Vol. 17, No.2 (2020) structures. It is a dry and eco-friendly technique. Plasma technology avoids waste production as found in wet-chemical processes. Both the feasibility of scale-up and economic aspects have to be regarded for the transfer of plasma technology into industry $(17,18)$. Plasma treatment alters the surface properties of a textile and makes it more adsorptive for nanoparticles. The consequence of an increased nanoparticle adsorption is the decreased content of nanoparticles in the bath ${ }^{(17,18)}$. The so-called nonthermal plasma is used to treat textiles. It enables substrate reactions to take place without its thermal degradation ${ }^{(19,20)}$. Plasma is created by using different systems of electrical power such as the direct, radiofrequency, and microwave systems ${ }^{(21,22)}$. Plasma treatment introduces new functional groups and active species on textile surface. Increasing the time of treatment with plasma leads to increase the formed sphere of etching and subsequently increases Nano- or micro roughness of the surface substrate (23-26). The concentration of carbonyl, carboxylic, and hydroxyl functional groups on the surface of cotton fabric depends on the used (water vapor, oxygen, nitrogen or air) ${ }^{(27-30)}$. The roughness of the surface is increased by means of plasma etching, where plasma causes desorption and elimination of by-products on the substrate. To achieve a high degree of substrate roughness, the treatment time and the reactor power must be higher. $\mathrm{ZnO}$ nanoparticles have been adsorbed poorly onto cotton fibers, so it is necessary to use high concentration of $\mathrm{ZnO}$ nanoparticles. An increased adsorption of $\mathrm{ZnO}$ nanoparticles by means of low-pressure plasma is created in wet tetrafluoromethane.

\section{Modification of Natural Fibers}

Natural fibers and textiles have been used for humans since ancient times. Our antecessors firstly used fur and animal skin for dressing and protection from the environment, but very soon they started to use vegetal fibers to make rudimentary fabrics. There are evidences of the use of dyed flax fibers into clothes more than 30,000 years ago ${ }^{(17)}$. For centuries, humans have used vegetal fibers (such as flax or cotton) and animal fibers (such as wool or silk) to produce yarns and then weave them into textiles using handmade processes.

\section{Functionalization of Cellulose Fibers}

Nowadays, there is a new revolution on the textile industry with the apparition of new technologies that could add special functions and properties to the fabrics. For example, there has been significant improvement in technologies 
for textile coloring, digital printing on textiles, smart fabrics, and high performance functional textiles. In this sense, nanoparticles play a key and significant role in this technological evolution ${ }^{(20)}$.

Treatment with Oxygen Plasma and $\mathrm{ZnO}$ Nanoparticles

Recently, interest is focused on the use of $\mathrm{ZnO}$ nanoparticles because the decreasing of the size of the particles led to increasing the surfaceto-mass ratio and consequently changing the chemical, mechanical, and optical properties of the fabric ${ }^{(31-37)}$. $\mathrm{ZnO}$ nanoparticles have excellent UV protective properties but have poor adsorption capacity towards textile materials. Low-pressure oxygen plasma created by an electrode less radiofrequency (RF) discharge was applied on cotton fibers in order to improve adsorption properties towards zinc oxide $(\mathrm{ZnO})$ nanoparticles and increase ultraviolet (UV) protective properties of the fabric. Cotton samples were treated with oxygen low-pressure RF plasma for different periods of time $(10,20$ and $30 \mathrm{~s})$ and functionalized with $3 \%$ of $\mathrm{ZnO}$ nanoparticles. The chemical and physical surface modifications of plasma-treated cotton fabric were examined by X-ray photoelectron spectroscopy (XPS) and scanning electron microscopy (SEM). The mechanical properties of plasma-treated samples were evaluated by measuring the strength and elongation of cotton fabrics. The quantity of zinc on the $\mathrm{ZnO}$-functionalized cotton samples was determined using inductively coupled plasma mass spectrometry (ICP-MS). The effectiveness of plasma treatment for UV protection properties of cotton fabrics was evaluated using UV-VIS spectrometry by measuring the UV protection factor (UPF). The results indicated increasing the time of plasma treatment leads to increasing the concentration of oxygen functional groups and roughness of the surface of fibers. These results lead to increasing the content of $\mathrm{ZnO}$ nanoparticles on the fibers and improving UPF of treated cotton up to $65.93^{(31)}$. Increasing plasma treatment time results in decreasing $\mathrm{C}-\mathrm{C}$ bonds and increasing $\mathrm{C}-\mathrm{O}$ bonds. The highest increase of $\mathrm{C}-\mathrm{O}$ bonds is attained after $30 \mathrm{~s}$ with oxygen plasma treatment. Longer plasma treatment time causes more grooved and etched surface of the fibers, enhancing the roughness of the fibers surface. Such physical changes of surfaces affect the mechanical properties of substrate. The decrease of the textile mechanical properties indicate that the plasma etching effect occurred on the surface and bulk of the fibers. It can be observed that untreated sample has the lowest value of breaking strength and elongation. Treating cotton fabric with plasma for $10 \mathrm{~s}$ increases the breaking strength for $18 \%$ and breaking elongation for $9 \%$. The reason for increased mechanical properties of plasma-treated cotton fabrics is probably due to the interlocking of microfibrils on the surface of fabric. Plasma treatment enhances inter yarn and inter fiber friction due to etching. The excellent UPF was achieved on plasma-treated cotton fabric functionalized with $\mathrm{ZnO}$ nanoparticles. Durability of treatments to washing was performed for one and ten home washing cycles. After one performed wash, the UPF does not decrease extensively. The untreated sample retains the UPF rating of 30, while the UPF rating decreases for plasma-treated for 10 and $20 \mathrm{~s}$ from $50+$ to 30 and 40 , respectively. The sample treated with plasma for $30 \mathrm{~s}$ retains the UPF rating $50+(\mathrm{UPF}=57.70)$, meaning that it has the best wash stability ${ }^{(31)}$.

\section{Treatment with Chitosan}

$\mathrm{ZnO}$ nanoparticles are an excellent blocker of UV radiation. Researches so far have proved that UV protection of cotton fabrics improves when being treated with $\mathrm{ZnO} /$ chitosan nanoparticles, increasing in intensity when treated with higher concentrations of nanoparticles of $\mathrm{ZnO} /$ chitosan. UV protective properties of cotton fabrics depend on the size of $\mathrm{ZnO}$ nanoparticles. Smaller particles of $\mathrm{ZnO}$ offer better protection from harmful UV radiation than larger particles. The application of $\mathrm{ZnO}$ nanoparticles to textiles is primarily carried out by means of wet-chemical procedures, using synthesized or ready-made $\mathrm{ZnO}$ nanoparticles. Synthetized $\mathrm{ZnO}$ nanoparticles are applied to cotton fabrics by impregnating with a wet pickup of $100 \%$, drying, and curing or by treating the fabric in a bath for 10 minutes using a magnetic stirrer, drying, and curing. Textiles functionalized in such a manner offer sufficient, yet rarely excellent UV protective properties (38- 52). Poor adsorption of $\mathrm{ZnO}$ nanoparticles to textiles was observed. Acrylic and epoxy binding agents can be added to the treating bath to increase the adsorption of $\mathrm{ZnO}$ nanoparticles. To achieve good protective properties, high concentrations of $\mathrm{ZnO}$ nanoparticles need to be used, meaning that most of them remain in the bath, eventually being released to the environment where they cause pollution.

Cotton textiles are dyed mostly with reactive dyes because they produce bright colors with excellent color fastness to washing. However, reactive dyeing requires considerable quantities 
of inorganic salt and alkali for efficient utilization and application of dyes. These salts and alkalis when drained to effluent generate heavy amounts of total dissolved solids leading to environmental pollution. Substantial remedies are being considered within the textile processing sector to reduce the effluent pollution and to fulfill the environmental regulations. So, cotton fabrics pretreated with plasma / nanochitosan and reactive dyeing carried out without salt. Plasma and chitosan nanoparticles were used for developing salt free ecofriendly dyeing. The effect of plasma and chitosan nanoparticles in color strength (K/S value), color difference, color fastness to crocking and washing of the dyed cotton fabric was investigated. The cotton fabric treated with plasma and 0.3 per cent Nano chitosan had higher $\mathrm{K} / \mathrm{S}$ values ${ }^{(38)}$.

Current union dyeing processes rely on one or two dye baths with one or two dyes for cotton/nylon blend fabrics. For 50:50 cotton/ nylon fabrics, cotton is dyed first under alkaline condition with reactive dyes and then the nylon is dyed with acid dyes under acidic condition. Atmospheric plasma/nanochitosan treatment as an environmentally friendly method was employed to modify surface properties of cotton/nylon blend fabrics to develop union dyeing with acid dyes. Cellulose fibers when immersed in water produce a negative electro-kinetic potential. The negative charge on the fiber repels the anionic dye ions and consequently the exhaustion of the dye bath is limited. When the fabric is treated with chitosan, the primary hydroxyl groups of cellulose is partially modified into amide groups, which intern leads the cellulose to act like as polyamide fiber. The possibility of one bath dyeing of plasmachitosan pretreated cotton/nylon fabric with acid dyes was carried out. Plasma treated cotton/nylon surface characteristics were evaluated using FTIR. The surface activation using air plasma introduces different functional groups in cotton/nylon blend fabric. The effect of plasma/nanochitosan pretreatment on dye ability, fastness, and few physicochemical properties has been investigated. The cotton /nylon sample treated with $0.3 \%$ of chitosan nanoparticles had higher $\mathrm{K} / \mathrm{S}$ values, washing, and crocking fastness. New method of union dyeing showed good fastness properties and offers the option of eco-friendly ${ }^{(39)}$.

\section{Flame Retardant Cellulose Fibers}

The permanent fire proofing of natural textiles such as cotton is still challenging because only a surface treatment can be applied. Moreover, to be resistant to washing or harsh weather conditions the flame retardant must be fixed strongly to the surface via covalent bonds. The grafting of fire retardant monomers on cotton fabric induced by argon plasma have been investigated with four acrylate monomers containing phosphorus, diethyl (acryloyloxyethyl) phosphate (DEAEP), diethyl-2- (methacryloyloxyethyl) phosphate (DEMEP), diethyl (acryloyloxymethyl) phosphonate (DEAMP) and dimethyl (acryloyloxymethyl) phosphonate (DMAMP). The plasma-induced graft-polymerization (PIGP) of diethyl (acryloyloxyethyl) phosphoramidate (DEAEPN) and acryloyloxy1,3-bis (diethylphosphoramidate) propan (BisDEAEPN) on cotton fabrics was reported. The flame retardant effect was compared with the previously used monomers. DEAEPN and BisDEAEPN exhibit the highest LOI values (28.5 and 29.5 respectively). The good flame retardant properties of these phosphoramidate monomers are attributed to the presence of nitrogen which causes a synergistic enhancement in the efficiency of phosphorus-based flame retardants. The fire retardant character of the treated fabrics was investigated by thermogravimetric analyses and LOI measurements ${ }^{(53)}$.

El-Hady et al. proposed a novel flame retardant approach based on the use of zinc oxide $(\mathrm{ZnO})$ nanoparticles for their application to cellulosic fabrics (cotton polyester blend) ${ }^{(38)}$. A pad-drycure method was selected to incorporate the $\mathrm{ZnO}$ nanoparticles onto the fabrics. The use of two different polycarboxylic acids such as succinic acid (SA) or 1,2,3,4-butane tetarcarboxylic acid (BTCA) together with sodium hypophosphite (SHP) as catalyst have been employed for crosslinking fabrics. The effect of curing temperature was investigated. It has been demonstrated that an increase of the curing temperature from $160^{\circ}$ to $180{ }^{\circ} \mathrm{C}$ could form ester cross-linking between cellulose chains and poly carboxylic acids (40). The measuring of char yield was performed to study the influence of flame retardant. The results indicated that both SA and BTCA are effective agents in reducing flammability of treated fabrics in the presence of SHP. Better experimental results were observed for BTCA in comparison with SA in reducing flammability. Increasing the nano$\mathrm{ZnO}$ concentration (from 0.25 to $0.5 \%$ ) as well as BTCA and SHP concentrations led to decrease the fabric flammability. 
The possibility of using atmospheric pressure dielectric barrier discharge plasma treatment for textile surface activation to facilitate deposition of nano- $\mathrm{TiO}_{2} / \mathrm{SiO}_{2}$ onto cotton fabric is investigated. It is aimed to develop a multifunctional cotton textile using plasma and nanotechnology. The treated fabric is evaluated through measuring the ultraviolet protection factor, antimicrobial activity, and flame retardancy as functional finishes. Surface morphology (Scanning electron microscopy, SEM), thermogravimetric analysis, and mechanical properties were also studied. SEM shows deposition of nanoparticles onto the fabric. $\mathrm{He}-\mathrm{O}_{2}$ plasma pretreatment improves the flame retardancy, antibacterial activity, and thermal stability of the samples was compared with the untreated samples ${ }^{(54)}$.

$\mathrm{N}$-methylol dimethylphosphonopropionamide flame retardant agent (FR) combined with a melamine resin crosslinking agent (CL) and a catalyst (phosphoric acid, PA) is used to enhance the flame-retardant of cotton fabrics. Titanium dioxide $\left(\mathrm{TiO}_{2}\right) /$ nano- $\mathrm{TiO}_{2}$ co-catalyst is added to the FR formulation to enhance the crosslinking of the FR-CL-PA components. Atmospheric pressure plasma is used as a pre-treatment, to enhance the fabric properties by a sputtering or etching effect. The Kawabata Evaluation System for Fabrics (KES-F) was used to determine the tensile, shearing, bending, compressional and surface properties. The specimens after FR treatment had worse tensile, bending, compression, surface friction and variation properties; an improvement was observed only in the shearing properties. Plasma pre-treatment improved tensile and compressional properties of the FR-treated specimens, while the shearing and bending, as well as the surface friction and variation properties, were affected negatively ${ }^{(55)}$.

\section{Proteinic Fibers}

Silk Fabric

Silk is an animal fiber and it is also called protein fiber. Silk is only natural fiber which is found in filament form. Silk is produced by insects. It is an excellent natural fibrous material with notable gloss and softness, good moisture absorption, and breathability. Owing to silk superior properties, it has been considered as one of the popularly used textile materials and also as the queen of textiles (56). Fabrics produced from silk are distinctly luxurious and possess a number of outstanding qualities such as luster, wearing comfort, fine and smooth texture, soft handle, and excellent draping quality. Over the years natural silk has been used conventionally in textiles because of its inherently elegant sheen, great flexibility, environmental friendliness and excellent mechanical strength ${ }^{(56)}$. As a natural protein fiber, silk possesses a chemical structure very similar to human skin with smooth, breathable, soft, non-itching and antistatic characteristics, which endow it a suitable material for high grade clothing (57). Potential defects of silk fabrics include their tendency to crease easily during home laundering, tendering nature when wet and easy microbial attack due to its hygroscopic nature ${ }^{(1,58)}$. Since silk can be easily attacked by bacteria ${ }^{(10,11)}$, which can cause damage to fibers in the silk products and even bring about skin diseases, it is preferred to be modified to show the antimicrobial activity in order to widen its scope of end uses ${ }^{(12,13)}$. Bacteria can adhere easily and grow on silk, and can result in its degradation and deformation. Its use is greatly hindered by hard conditions of storage ${ }^{(59)}$. Hence, it is much preferable to modify silk fabrics to show the antimicrobial activity in order to widen its scope of the end uses. Antibacterial finishes are applied to textiles for three major reasons, namely, to prevent the spread of disease and avoid the danger of injury-induced infection, to limit the development of odour from perspiration, stains and soil on textile materials and to prevent the deterioration of textile caused by mildew ${ }^{(60)}$. Compared with organic reagents, inorganic Nano-materials, especially PtNPs, are stable and effective for antimicrobial applications ${ }^{(12)}$. PtNPs have high activity ${ }^{(14,15)}$ and selectivity for catalytic reaction. They can enhance the cleansing function of skin surface.

Plasma Pretreatment on Tasar Silk Fabrics Coated With ZnO Nanoparticles against Antibacterial Activity

It is well known that plasma pretreatment is an eco-friendly process employed to modify the surface properties and improve the adhesion properties of tasar silk fabrics. The plasma pretreatment has been carried out in DC glow discharge plasma at constant power and for different treatment durations $(5,10$ and 30 min). Since $\mathrm{ZnO}$ nanoparticles ( $\mathrm{ZnO} \mathrm{NPs}$ ) play a significant role in antibacterial, cleaning and UV protection, $\mathrm{ZnO}$ NPs have been synthesized by the wet chemical method. Plasma treated silk fabrics are coated with $\mathrm{ZnO}$ NPs using vacuum thermal evaporation technique. Structural and chemical change of raw, untreated and plasma treated silk fabrics coated with $\mathrm{ZnO}$ NPs are analyzed by XRD and attenuated total

J. Text. Color. Polym. Sci. Vol. 17, No.2 (2020) 
reflection Fourier Transform infrared (ATRFTIR) studies. The surface morphologies of all the fabrics are analyzed by using scanning electron microscope (SEM), which confirms the adherence of $\mathrm{ZnO}$ NPs on the surface of the fabrics. Elemental analysis is carried out using energy dispersive spectroscopy, which confirms the presence of $\mathrm{ZnO}$ NPs on the surface of the fabrics. The improved surface property in terms of hydrophobicity is analyzed by using a contact angle test. It is found that the plasma pretreated silk fabrics coated with $\mathrm{ZnO}$ NPs have better antibacterial activities against Escherichia Coli bacteria $^{\left({ }^{(61)}\right.}$. $\mathrm{ZnO}$ coated and plasma pretreated silk fabrics showed excellent antibacterial activity against E. Coli bacteria. This coating approach is a dry clean process that avoids waste. Plasma pretreatment on silk fabrics improves the adhesion of $\mathrm{ZnO}$ NPs. The silk surface coated with $\mathrm{ZnO}$ NPs has been characterized using XRD, ATR-FTIR, contact angle, SEM, EDS, TGA and antibacterial test. Characterization of XRD and ATR-FTIR on raw and coated fabrics signs that bulk properties of fabrics do not change. Contact angle measurement clearly shows that the hydrophobic nature of coated fabrics can be increased with plasma pretreatment. SEM analysis shows the improvement of the adsorption on plasma treated fabric and EDS shows the presence of $\mathrm{ZnO}{ }^{(61)}$. The antibacterial activity and thermal stability improve significantly after plasma pretreatment.

\section{Effect of Coating Time on LPP Treated Silk Fabric Coated With ZnO Nanoparticles}

Zinc oxide nanoparticles have remarkable properties that play a role in antifungal and antibacterial properties to static electricity and UV protection as well. This is an outstanding property to develop industrial and medical sites. It was also an important role in the textile industry as well. LPP of materials has become an attractive method in the modification of surface chemical and physical properties without affecting the bulk material ${ }^{(62)}$. The clean technology reduced environmental pollution because it uses less water and chemicals. It is an improvement over the original surface and does not affect the quality of the material itself. By keeping the texture of silk, the low pressure plasma $\mathrm{ZnO}$ nanoparticles substance that can bind to water ${ }^{(63)}$. The $\mathrm{ZnO}$ nanoparticles was able to change the properties of oriented surface fibers of silk because these particles created new chemical bonds with molecular constituents of silk fibers or could be inserted into the structure of molecules using milling (etching) the surface of silk fibers
(63). The effect of coating time on the coating of $\mathrm{ZnO}$ nanoparticles on low pressure plasma (LPP) treated silk fabric was studied, aiming at improving the $\mathrm{ZnO}$ coating on silk. Silk fabric was treated with LPP with conditions of power 50 and 100 Watts at radio frequency of $13.56 \mathrm{MHz}$ under argon atmosphere with the pressure of 100 mTorr and holding time for 5 minutes. After LPP treatment, the fabric samples were coated with $\mathrm{ZnO}$ nanoparticles using dip coating technique with variation of treatment time $(5,25,45$ and 60 minutes). The results showed that coating time of 45 minutes exhibited the optimum coating of $\mathrm{ZnO}$ nanoparticles. It was found that LPP treatment could enhance the hydrophobicity of silk fabric when compared with that of untreated sample. Morphology of the samples was determined using scanning electron microscopy technique (SEM) ${ }^{\left({ }^{62}\right)}$. Plasma treatment results indicated a pronounced change in the surface properties of silk at the R.F. 100 Watt in LPP process. Higher discharge power leads to more significant increase of the contact angle in comparison with surface wettability. The optimum condition was reached with coating of $\mathrm{ZnO}$ nanoparticles with $2 \% \mathrm{w} / \mathrm{w}$ concentration for 45 minutes. SEM measurement shows the coat of $\mathrm{ZnO}$ nanoparticles on silk surface. It was found that deposition of $\mathrm{ZnO}$ could be performed onto the silk fabric through plasma treatment.

\section{Wool Fibers}

Wool fiber ${ }^{(64)}$ is one of the most natural fibers employed considerably in textile industry. It is composed of keratinous protein as a basic constituent and the minor component cell membrane complex (CMC). CMC forms a continuous phase in the fiber, links cortical and cuticular cells. The cuticular cells are located on the outermost part of the fiber surrounding the cortical cells. The surface of these cells is hydrophobic nature due to the presence of a fatty acid monolayer covalently bounded to the epicuticle layer ${ }^{(65-67)}$. External layer of the fiber is a bundle of cells which have a structure of scales. The scales having relatively hard and sharp edges act as a barrier for the diffusion, which adversely affects the sorption behavior of wool fibers. Scaly structure determines performance and quality of the finished wool fabric such as handle, luster, pilling, dye-ability, felting, and shrinkage. To overcome shrinkage and hydrophilicity disadvantages of wool, various surface modification methods on fiber surface are necessary. Chemical methods were the major treatment for eliminating these 
problems in the past. However, the increasing environmental pressure has motivated textile industry to use ecological processes, such as enzyme, plasma and biopolymers instead of chemical treatments. In addition to escape potential chemical pollutants and their effluents as a result of chemical processes, bulk properties of fabric can be protected ${ }^{(64)}$.

\section{Treatment of Wool with Nano Chitosan}

Different techniques of surface modification on surface of fiber are required so as to overcome the problems associated with shrinkage and hydrophilicity of wool. Chemical methods have been the major treatment for eliminating such problems earlier. But, owing to the increasing environmental pressure, textile industry has been encouraged to use ecological processes, like enzyme, plasma and biopolymers in place of chemical treatments. Besides escape potential chemical pollutants and their effluents as a result of chemical processes, bulk properties of fabric can be protected. A renewable polysaccharidebased cationic biopolymer, chitosan, is derived from the chitin component of the shells of crustaceans ${ }^{(64-67)}$. It can be seen as a suitable candidate for replacing some synthetic polymers with advantageous properties including nontoxicity, biocompatibility, biodegradability, antimicrobial activity and chemical reactivity. It can be used mainly for the purpose of shrink resistance, dye-ability, antimicrobial effect in wool finishing treatments. In order to reduce wool damage, chitosan application before enzyme treatment is used in many studies ${ }^{(68-71)}$. Because of its poly cationic character, it has an interaction with oppositely charged molecule or surfaces of enzymes and wool fibers. On the other hand, it can be removed partially from the fabric surface depending on washing conditions. The combination of appropriate treatment/chemical agents would be beneficial to provide the stability against multiple washings. To obtain more advantages of chitosan, new studies have been focused on Nano sized chitosan particles. In textile industry, Nano chitosan usage is relatively new subject. Nano-particles possess unique properties, such as large ratio of surface to volume, surfaceactive multi-centers and high surface reactivity. Nano chitosan is bioactive and frequently used in many industrial areas including textiles ${ }^{(72-79)}$.

Plasma treatment is offering an attractive alternative to add new functionalities such as water repellence, hydrophilicity, mechanical, antibacterial properties, etc. due to the Nano scaled modification on textile fibers. At the same time, the natural aspect of fiber properties as well as the handle of the material remains unaffected. For wool fabrics, plasma treatments are replacing chemical textile treatments to achieve shrinkresistance and improved dye-ability. Also, additional effects can be achieved such as modification of the cuticle layer, generation of new hydrophilic groups as a result of hydrocarbon chain oxidation, reduction of the chain length of fatty acids, improving of surface wettability, dye-ability, fiber cohesion, and shrink resistance. Atmospheric plasma treatments have significant advantages in large-scale textile applications in terms of the expense, time and space in comparison to the vacuum plasma applications (64). Bulk chitosan and nanochitosan particles were used. All treated fabrics were evaluated in terms of their antimicrobial effect, dyeing by acid dyes, air permeability, and tensile strength and surface morphologies. For antibacterial treatments, Agloaded chitosan particles were synthesized as well. Different treatments (enzyme, plasma and enzyme + plasma combinations) were applied to modify the wool surface to enhance biopolymer particles effect and to obtain desired properties ${ }^{(64)}$.

Wool fabrics are subjected to different surface modification methods in order to improve their hydrophilicity, dyeability, antimicrobial, shrink proofing properties. Especially environmental friendly methods and application of biopolymers are gaining importance instead of conventional processes and textile chemicals. Nano chitosan particles were synthesized, applied on wool fabrics and compared with bulk chitosan in terms of various properties. Ag-loaded chitosan nanoparticles was also synthesized and examined in terms of its antibacterial activity by different application methods. It has more than $95 \%$ antibacterial effect against gram positive and negative bacteria. The influences on hydrophilicity, antibacterial activity, dyeing, air permeability, surface morphology and tensile strength were studied. Enzyme and atmospheric plasma treatments were used both alone and combined treatments before application of chitosan/Nano chitosan to increase their effects. Enzyme and plasma treatments showed significant contributions on chitosan and Nano chitosan in wool properties. Combined treatments caused a smoother surface on wool fabrics. Improved hydrophilicity and dyeability properties could be obtained by ecological methods. The effect of 
nylon and other polyamide fabrics will continue unabated throughout the $21^{\text {st }}$ century. The main benefit of polyamide fabric is its elasticity, and consumers also prize it for its softness. Beyond the world of apparel, nylon and other polyamides have found seemingly permanent homes in scientific and industrial markets. A surprising number of consumer goods are made with polyamides; for instance, many different automotive parts are made with these materials as are toothbrushes, hair combs, firearm components, and various types of food packaging ${ }^{(100)}$.

\section{Polyester}

Polyester (PE) fiber is a category of polymers that contain the ester functional group in their main chain. As a specific material, it most commonly refers to a type called polyethylene terephthalate (PET). Fabrics woven or knitted from polyester thread or yarn are used extensively in apparel and home furnishings, from shirts and pants to jackets and hats, bed sheets, blankets. Industrial polyester fibers, yarns and ropes are used in car tire reinforcements, fabrics for conveyor belts, safety belts, coated fabrics and plastic reinforcements with high-energy absorption. Polyester fiber is used as cushioning and insulating material in pillows, comforters and upholstery padding. Polyester fabrics are highly stain-resistant ${ }^{(\mathbf{1 0 1})}$.

Treatment of Synthetic Fibers with Nanoparticles Treatment with Titanium Dioxide TiO2

The scanning electron microscopy (SEM) investigates the surface morphology of the plasma-treated polyester surface before and after $\mathrm{TiO}_{2}$ coating. It is concluded that the surfaceetching process occurs on the surface of oxygen plasma-pretreated fiber, keeping and remaining the bulk properties with no change. Granules, micro craters, and ripple-like structures of sub micrometer size are formed on the oxygen plasma-pretreated surface ${ }^{(102,103)}$. The removal of the surface layers leads to an increase in the surface roughness which is far more accentuated than that of the original fiber surface. In contrast to the original polyester filament, the surface structure of the $\mathrm{TiO}_{2}$-coated polyester filament pretreated with oxygen plasma indicates the formation of $\mathrm{TiO}_{2}$ layers. The change in the chemical composition on the polyester surfaces occurring in the oxygen plasma pretreatment process and the relative amount of $\mathrm{TiO}_{2}$ deposited on the polyester surface without and with oxygen plasma pretreatment were investigated by XPS. It was found that oxygen plasma pretreatment led to an increase in oxygen concentration and a decrease in carbon concentration due to the plasma oxidation of polyester substrates, thus indicating the creation of oxygenic functional groups $\left(-\mathrm{CO}^{-}, \mathrm{COO}^{-}\right)$on the polyester filament surface ${ }^{(103,104)}$. The relative element content in the $\mathrm{TiO}_{2}$-coated polyester surface without and with oxygen plasma pretreatment shows that $\mathrm{Ti}$ percentage in the $\mathrm{TiO}_{2}$-coated polyester surface with oxygen plasma pretreatment was larger than that in the $\mathrm{TiO}_{2}$-coated polyester surface without oxygen plasma pretreatment. This means that the oxygen plasma-pretreated polyester surface is beneficial for the formation of $\mathrm{TiO}_{2}$ coating which enhanced the increase in the quantity of $\mathrm{TiO}_{2}$ on polyester filament pretreated by oxygen plasmas. This can be attributable to the increase in the roughness of polyester filament surface ${ }^{(102)}$ and the introduction of negative groups $\mathrm{COO}^{-},-\mathrm{O}$ $\mathrm{O}^{-}$at the polyester surface ${ }^{(103)}$, to which $\mathrm{TiO}_{2}$ can attach through ionic attraction with the positively charged $\mathrm{Ti}^{4+}$ of $\mathrm{TiO}_{2}{ }^{(105)}$

The bactericidal activities under UV irradiation (UV intensity was about $35 \mu \mathrm{W} / \mathrm{cm} 2$ ) of $\mathrm{TiO}_{2}-$ coated polyester with oxygen plasma pretreatment according to a modified procedure of the shaking method (ASTM E2149-01) ${ }^{(\mathbf{1 0 6})}$, in which a Grampositive bacterium $\mathrm{S}$. aureus was used to assess the activities was investigated. It is concluded that $\mathrm{S}$. aureus was completely killed on the $\mathrm{TiO}_{2}$-coated polyester substrate pretreated with oxygen plasma within $5 \mathrm{~h}$ under UV irradiation, which means that the $\mathrm{TiO}_{2}$ coated polyester substrates showed excellent bactericidal activities. Furthermore, the $\mathrm{TiO}_{2}$ coated polyester substrate pretreated with oxygen plasma showed higher bactericidal activity than the original substrate which may be due to greater deposition of $\mathrm{TiO}_{2}$ particles on the polyester surface after oxygen plasma treatment and in turn nullify the viable bacteria. The UV absorption of the $\mathrm{TiO}_{2}$-coated polyester substrate pretreated with oxygen plasma according to the Australian/New Zealand Standard demonstrated a very high ultraviolet protection factor (UPF) value compared to the original fiber surface. This may be attributed to greater deposition of $\mathrm{TiO} 2$ particles on the polyester surface resulting from the increase in the roughness ${ }^{\left({ }^{102}\right)}$ demonstrated in SEM above and the introduction of negative groups $\mathrm{COO}-,-\mathrm{O}-\mathrm{O}-$ onto the polyester surface ${ }^{(\mathbf{1 0 3})}$ after oxygen plasma pretreatment. These results indicate that the $\mathrm{TiO}_{2}-$ coated polyester substrate can provide excellent protection classification. A higher UPF and stronger UV absorption power are achieved after oxygen 
enzyme, plasma and Nano chitosan treatments led to 2.5 times higher $\mathrm{K} / \mathrm{S}$ values than that of untreated fabric. All treatments had no detrimental effects on bulk properties of fabrics ${ }^{(64)}$.

Chitosan nanoparticles and chitosan/silver nanoparticles were synthesized (75- 78). Enzyme and plasma treatment contributions of Nano chitosan treatments on wool fabrics were investigated in terms of various properties. Comparison of chitosan and Nano chitosan in dyeing, antimicrobial effect, tensile strength, and surface morphology and air permeability properties was investigated. Chitosan addition on the wool surface generates additive functional groups which cause increase in hydrophilicity. Protease enzyme has hydrolytic effect on wool fibers and the diffusion barrier to water and dye molecules can be overcome. Plasma treatment enhances capillarity by means of oxidation and etching reactions. Dual effects of enzyme, plasma and chitosan showed significant improvements while triple effects gave the best results. Chitosan, enzyme and plasma treatments alone increase dye uptake of wool by different mechanisms to a great extent compared to the control sample. Enzyme and plasma treatments facilitate dye diffusion prior to chitosan treatment. Enzyme + plasma + chitosan combined treatments improves $\mathrm{K} / \mathrm{S}$ values in comparison to untreated one with good fastness properties. Nano chitosan showed better properties due to its large surface area and smaller size when compared with bulk chitosan. Chitosan showed 93, 98\% effect against gram negative bacteria with combined treatments of enzyme and plasma. Chitosan silver nanoparticles showed the highest antibacterial effect on fabrics up to $97,66 \%$. Nearly $100 \%$ antibacterial effect was achieved by means of enzyme and plasma pretreatments prior to chitosan-silver nanoparticle application. Enzyme treatment caused the loss of tensile strength in acceptable limits. However, post application of chitosan or Nano chitosan showed protective effect and improved tensile strength. Enzyme, plasma and chitosan decreased permeability to a certain degree ${ }^{(64)}$.

Treatment of Wool with Plasma/ Nano Silver

One of the more effective anti-bacterial methods currently under investigation is based on the design of a coating that contains silver ${ }^{80-}$ 82). Silver is effective in killing over 650 diseasecausing organisms. Silver is active against gram-negative bacteria, such as Pseudomonas Aeruginosa, as well as gram-positive bacteria, fungi and certain viruses. It was reported that low concentrations of silver is non-toxic. Monovalent silver is non-toxic to mammalian cells ${ }^{(\mathbf{8 0 - 8 2})}$. It is hypothesized that $\mathrm{Ag}$ /plasma polymer films may offer long-term resistance to bacterial adhesion. Ag/plasma polymer Nano-composite materials, consisting of Nano-scaled metal clusters embedded within a plasma-polymer matrix, can be deposited using a mixed plasma polymerization/ sputtering process ${ }^{\mathbf{8 3}, \mathbf{8 4})}$. The plasma deposition of Nano-Ag/plasma polymer films can be described as a mixed process, including the deposition of a plasma polymer matrix and the sputtering of silver atoms at lower pressure ( $c a .0 .1 \mathrm{mbar}$ ) and higher input power than is commonly used for plasma polymerization. The deposition of Nano$\mathrm{Ag} /$ plasma polymer films can be considered as a compromise between having an acceptable quantity of silver to add an anti-bacterial property, and maintaining enough of the functionality of the matrix in order to confer additional properties of the coatings. Nano-particle quantity and characteristics of the films can be adjusted by altering deposition parameters such as power input, pressure and $\mathrm{Ar}$ feed ratio ${ }^{(\mathbf{8 4}-86)}$. Plasma $\mathrm{Ag} / \mathrm{PEO}$-like coatings completely prevented the adhesion of four different $P$. aeruginosa strains when deposited on medical grade PVC. Another example includes $\mathrm{Ag}$ /Teflon-like coatings which were also capable of reducing adhesion of $\mathrm{P}$. aeruginosa strain. It was demonstrated that increasing the Ag-content, through changes in input power, allowed for an increased reduction in bacterial adhesion.

\section{Treatment of Wool with Cyclodexterine}

Undesirable side effects are caused by the use of textile chemicals. Plasma need less energy and water to perform functional characteristics. Textile industries see a promising future for plasma technology, with the environmental and energy conservation benefits, in developing high-performance materials. Plasma technology, as a very active tool applied to wool to modify the surface substrate. The decrease in shrinkage, felting and pilling in the case of wool, polyester, polyamide and polyester has been caused by application of cyclodextrins ${ }^{(87)}$. On the other hand such application resulted in properties like antimicrobial, hydrophilic, soil-resistant, and so on. Cyclodextrins are nontoxic and biodegradable, there by offering "green" solutions to enhance the properties and providing new functionalities to textile products. An increase in the improvements on the application areas of nanotechnology in

J. Text. Color. Polym. Sci. Vol. 17, No.2 (2020) 
textile industry was carried out like anti-bacterial textiles, antistatic textile, flame-retardant textiles, and so on.

\section{Eco Friendly Coating of Wool / Polyester}

One of the widely used blend textile materials in the textile industry is wool/polyester fabric. Investigation has been carried out regarding the self-cleaning finishing of this fabric ${ }^{(\mathbf{8 8}-91)}$. The loading of titanium dioxide nanoparticles have been improved by pretreatments using lipase enzyme and potassium permanganate as oxidizing agent. The adsorption of titanium dioxide Nanoparticles on fibers has been improved by oxygen plasma treatment which introduces oxygen containing functional groups to the surface of wool and polyester fibers and removes the hydrophobic scales of wool. This is affected without yellowing and affecting the physical properties of the fabric. The wool/polyester fabric was treated with oxygen plasma and then coated with $\mathrm{TiO}_{2}$ nanoparticle and the self-cleaning property of the finished fabric was evaluated. Plasma treatment has improved the amount of nanoparticle loading on the fabric. The plasma treated and coated samples with $\mathrm{TiO}_{2}$ exhibit better self-cleaning property compared with noncoated and raw coated samples ${ }^{(\mathbf{9 0})}$. The physical properties of the fibers can be preserved by plasma treatment which can substitute processes like oxidizing and enzyme pretreatments that do not consume water and chemicals.

\section{Modification of Synthetic Fibers}

The conventional textile finishing techniques are wet chemical modifications where water and rather hazardous chemicals are used in large quantities and wastewaters need to be processed before discharging effluent, whereas the most problematic factor are ecological impacts to the environment and effects to human health. The increasing environmental concerns and demands for an environmentally friendly processing of textiles leads to the development of new technologies, the use of plasma being one of the suitable methods ${ }^{(92)}$. Plasma technology is an environmentally friendly technology and a step towards creating solid surfaces with new and improved properties that cannot be achieved by conventional processes ${ }^{(93)}$. The continuous advances in organic chemistry, especially with the apparition of polymer chemistry discipline, enable the fabrication of synthetic fibers which are made from polymers or small molecules, being the petroleum as the most important raw material.
Among the high amount of different types of synthetic fibers, the most known are polyamide, polyester, acrylic, and polyolefin. Within these four types, the polyamide (especially PA6, known as polyamide 6 or nylon) and polyesters (especially PET, known as polyethylene terephthalate) are the most used in the textile industry. Here, it is focused on the development of functionalized synthetic fibers, concretely polyamide and polyester fabrics. In general, these fabrics show poor wettability properties and hydrophobic in nature which can affect the polymer process ability and fiber dyeability ${ }^{(94)}$. With the development of the nanotechnology, different types of nanoparticles (mostly inorganic or metal oxide) have been successfully incorporated into synthetic fibers in order to obtain functionalized fibers with special properties ${ }^{\mathbf{9 5 - 9 8 )}}$. The major effects such as flame retardancy, antibacterial activity, or super hydrophobicity are presented in detail using different deposition techniques.

Plasma technology has been in use for the synthesis, processing, treatment, and deposition of polymers, Nano-particle or Nano-porous structures, textile surfaces, and etching, etc. Moreover, it is a clean and eco-friendly technique which minimizes waste, unlike wet-chemical processes. However, for mass-scale industrial production, both the feasibility of scale-up and economic aspects have to be given due consideration. Nanoparticles are very interesting because of their surface properties, different from bulk materials. Such properties make possible to endow ordinary products with new functionalities. More relevant contributions of the use of nanoparticles for functionalize textile materials. Their relatively low cost with respect to other Nano-additives make them a promising choice for industrial mass-production systems. Nanoparticles of different kind of materials such as silver, titania, and zinc oxide have been used in the functionalization of fibers and fabrics achieving significantly improved products with new macroscopic properties as well as providing new properties such as antibacterial activity, flame retardant properties, UV-protection, super hydrophobicity, and others ${ }^{(99)}$.

\section{Polyamide}

Polyamide (PA) fabrics represent about \%12 of global synthetic fiber production. The unique benefits of this type of fabric continue to accord it an integral place in many types of textiles, and it's practically guaranteed that production of 
plasma pretreatment. The stronger UV-absorption intensity implies higher photo activity. Therefore, the $\mathrm{TiO}_{2}$ coated polyester substrate pretreated with oxygen plasma would have higher photo catalytic activity than the $\mathrm{TiO}_{2}$ coated polyester substrate without oxygen plasma pretreatment.

The tearing strength of original polyester and $\mathrm{TiO}_{2}$-coated polyester pretreated with oxygen plasma, were studied. The study was carried out before and after $20 \mathrm{~h}$ of light irradiation in Xenon test Alpha LM light exposure and weathering test instrument. The tearing strength of $\mathrm{TiO}_{2}$-coated polyester substrates pretreated with oxygen plasma before light irradiation was reduced compared with that of the oxygen plasma-pretreated polyester. This could be due to the increase of stiffness after $\mathrm{TiO}_{2}$ coating. After $20 \mathrm{~h}$ of light irradiation, the tearing strength of original polyester, and $\mathrm{TiO}_{2}$-coated polyester substrates was reduced. However, the decrease in the original was nearly the double of the decrease in $\mathrm{TiO}_{2}$-coated polyester substrates. This suggests that there is no photo catalytic decomposition of the molecular chains of polyester caused by the titania layers. On the contrary, the titania layers reduced the decline of tearing strength due to its ability to absorb UV irradiation. This is agreement with the results of self-cleaning cotton in our previous work ${ }^{(107)}$.

\section{Treatment with Silver NPs}

In order to improve the interaction between hydrophilic colloidal silver NPs and hydrophobic fibers, corona treatment of PA and PE fabrics was carried out. Generally, PA and PE fabrics exhibit hydrophobic behavior and a low surface energy $(\mathbf{1 0 8 , 1 0 9 )}$ which were confirmed by the contact angle measurements. Contact angles of the treated PE and treated PA fabrics were decreased after corona treatment, demonstrating that the fibers became more hydrophilic. Significant increase in fabric wettability, which was especially pronounced in the case of PE fabrics, is suggested to be due to the oxidation of the fiber surface and the formation of new polar functional groups $(-\mathrm{OH},-\mathrm{COOH}$, etc.) during the corona treatment and through the post-plasma reactions ${ }^{(108-112)}$. The changes in fiber surface morphologies of PE and PA after loading of silver NPs were analyzed using the SEM technique. It is concluded that the untreated PE and PA fabrics loaded with silver revealed a low yield of unevenly distributed agglomerates of NPs on the fiber surface. Corona treatment positively affected the loading of silver onto both samples. Remarkable increase in the number of well-dispersed uniform silver NPs on the surface of corona-treated PE fibers was noticed compared to untreated ones. Unlike PE fibers, due to the aggregation of silver NPs, bigger assemblies were appeared on the surface of corona-activated PA fibers. The almost covered surface of coronatreated PE fibers with silver NPs and bigger aggregates of NPs on the surface of corona-treated PA fibers are probably the direct consequence of the chemical changes on the surface and increased hydrophilicity of both fibers induced by corona treatment which influence the binding efficiency of NPs from water-based colloidal solution. The increased number of carboxyl groups along with the presence of benzene rings in the polymer structure indicates the possibility of a strong interaction between PE fibers and silver NPs $(113,114)$. From the studies of benzoic acid and its derivate on the surface of silver NPs, it is well known that, the strong interaction between the $\mathrm{Ag}$ surface, benzene rings and carboxylic groups can be established. In addition to carboxylic groups, the polar amide groups take part in the interaction between PA polymers and silver NPs ${ }^{(115)}$.

Antibacterial effect for Gram-positive bacterium S. aureus and Gram-negative bacterium E. coli on PA and PE fabrics was studied by deposition of silver NPs from colloids. PA fabrics loaded with silver NPs from 10 ppm colloid have better antibacterial properties compared to PE fabrics. Antibacterial efficiency of silverloaded PA and particularly PE fabrics that were previously activated by corona was more prominent for E. coli. PA and PE fabrics double loaded with silver NPs from $50 \mathrm{ppm}$ colloid demonstrated significantly enhanced antibacterial properties and excellent laundering durability. Improved antibacterial properties of coronatreated fabrics can be attributed to higher fiber surface roughness and increased hydrophilicity, which made them more accessible to silver NPs (116). The antibacterial effect of both bacteria types on silver-loaded PE fabrics which were corona pretreated was almost not altered after washing, indicating the excellent laundering durability. Modification of Semisynthetic Fibers

\section{Viscose Fabric}

Viscose is a semi-synthetic type of rayon fabric made from wood pulp that is used as a silk substitute, as it has a similar drape and smooth feel to the luxury material. The term "viscose" refers specifically to the solution of wood pulp that is turned into the fabric. Viscose was first produced 
in 1883 as a cheaper, artificial silk. Viscose is made from tree wood pulp, like beech, pine, and eucalyptus, but can also be made from bamboo. Viscose is a semi-synthetic fibers due to the many chemicals involved in the viscose process, like sodium hydroxide and carbon disulfide. Viscose blends well with other fibers like cotton, polyester, and spandex. Viscose rayon does not trap heat, but it also absorbs water and sweat nicely, making it great for t-shirts and athletic wear. It is extremely airy, which makes it nice for blouses and summer dresses. It's a very light fabric that doesn't stick to the body, so it's optimal for warm weather clothing. While the material looks like silk, it feels like cotton. The fabric is not elastic but can be blended with other textiles, such as spandex, to add stretch. Viscose can hold dye without fading, even after long-term use and washes.

Nanoparticles Coated Viscose Fabric Using Low Temperature Plasma

Plasma processing technology aims to modify the chemical and physical properties of fabric surface. The nanotechnology creates the structure of excellent properties by controlling atoms, molecules and functional materials. For coating of pure textile viscose fabric by nanomaterial, The zinc oxide $\left(\mathrm{ZnO}_{2}\right)$ nanoparticles were prepared by sol-gel process, and were used for coating pure viscose material using tip coating methods for 1 hour. The nanoparticles coating viscose materials was analysed and characterized with, XRD, FTIR and SEM. These results showed that the fabric surface treated with plasma was modified when compared to the untreated fabric surface ${ }^{(52)}$. SEM of untreated and plasma treated $\mathrm{ZnO}_{2}$ coated viscose fabric shows that $\mathrm{ZnO}_{2}$ particles are not uniformly coated on the fabric, but uniformly dispersed on the fabric surface. The smallest particles appeared on the surface. After plasma treatment the fabric wettability was increased. The increase in wettability causes the increase in smoothness of the fabric surface. Plasma treatment using atmospheric air on $\mathrm{ZnO}_{2}$ nanoparticles coated viscose fabric was studied ${ }^{\text {(52). }}$. The comparative study of plasma treated and untreated viscose fabric was analyzed. The SEM results have confirmed the presence of $\mathrm{ZnO}_{2}$ on the fabric surface. Over all the results of this research shows that the surface property of the viscose fabric was modified when compared to untreated fabric.

\section{Cellulose Acetate}

Plasma treatments of cellulose and cellulose based materials (paper, cellophane, cotton linters, viscose fibers, cellulose acetate) can efficiently change their surface properties, such as wettability (e.g. reduction of their hydrophobic character and increase of wettability), surface energy and adhesion (to improve the strength of their adhesion to the matrix in composite materials). Plasma treatment has already been implemented in several laboratory studies, pilot-scale and also some industrial environments in order to modify surface characteristics of fibers and paper. An improvement of adhesion of inks, adhesion of metals and metal nanoparticles, and increase of the impermeability of a transparent film after printing was studied Using APPJ plasmas. The substrates were modified using atmospheric pressure plasma jets (APPJ). In addition, impregnation of nanoparticles assisted by plasma and compared it to spin coating process as a standard reference was studied. The applied nanoparticles $(\mathrm{Au}, \mathrm{Ag}, \mathrm{Cu})$ were synthesized by laser ablation techniques from elemental metals deposited in liquids. This led to improved surface properties decorated with nanoparticles ${ }^{(117)}$.

\section{References}

1- Periyasamy, A.P. and Venkatesan, H. Eco-Materials in Textile Finishing. In: Martínez L., Kharissova, O., Kharisov, B. (Ed.) Handbook of Eco-materials. Springer, Cham (2018).

2- Gokarneshan, N. "A Review of Some Significant Insights on Nano Finishing of Protein Fibres", $J$ Nanosci. Nanotechnol. Res., 2 (1:4), 1-9 (2018).

3- Karthikeyan, N., Vijayalakshmi, K.A. and Vignesh, K. "Study on nanoparticles Coated Viscose Fabric Using Low Temperature Plasma”, International Journal of Chemical and Physical Sciences, 4 (6), 94-98 (2015).

4- Huang, H.C., Ye, D. and Huang, B. "Nitrogen Plasma Modification of Viscose-Based Activated Carbon Fibres," Surface and Coatings Technology, 201 (24), 9533 - 9540 (2007).

5- Vrabic, U. and Jesih, A. "Physical and Absorptive Changes in Plasma Treated Viscose Fibers", Fibres \& Textiles in Eastern Europe, 15 (5-6), 64 -65 (2007).

6- Chan, C.M., Ko, T.M. and Hiraoka, H. "Polymer Surface Modification by Plasmas and Photons", Surface and Interface Analysis, 15 (6), 349-354 (1990).

7- Dubey, S.P., Lahtinen, M., Särkkä, H. and Sillanpää, M. "Bioprospective of Sorbus Aucuparia Leaf Extract in Development of Silver and Gold Nanocolloids", Colloids Surf, 80 (1), 26-33 (2010). 
8- Chen, W., Yan, J., Song, N., Li, Q. and Yang, B. "Study on Silver Nano Powder Prepared by Chemical Reduction with an Organic Reductant", Guijinshu (Pre. Met.), 27, 14-17 (2006).

9- Choi, N.K., Seo, D.S. and Lee, J.K. "Preparation and Stabilization of Silver Colloids Protected by Surfactant”, Materials Forum, 29, 394-396 (2005).

10- Jiangmei, Y., Huiwang, T., Muling, Z., Jun, T. and Zhang, S. "PVP-Capped Silver Nanoparticles as Catalyst for Oxidative Coupling of Thiols", Chin. J Catal, 30 (9), 856-858 (2009).

11- Setua, P., Chakraborty, A., Seth, D., Bhatta, M.U. and Satyam, P. "Synthesis, Optical Properties, and Surface Enhanced Raman Scattering of Silver Nanoparticles in Non-aqueous Methanol Reverse Micelles", J. Phys. Chem, 111 (10), 3901-3907 (2007).

12- Suh, W.H., Suslick, K.S. and Stucky, G.D. "Nanotechnology, Nano-toxicology and Neuroscience", Prog Neurobiol, 87 (3), 133-170 (2009).

13- Matyjas-Zgondek, E., Baciarelli, A., Rybicki, E., Syznkowska, M.I. and Kolodziejczyk, M. "Antibacterial Properties of Silver-Finished Textiles", Fibres Text Eastern Eur, 70 (5), 101-107 (2008).

14- Amato, E., Diaz-Fernandez, Y.A., Taglietti, A., Pallavicini, P. and Pasotti, L. "Synthesis, Characterization and Antibacterial Activity Against Gram Positive and Gram Negative Bacteria of Bio-mimetically Coated Silver Nanoparticles", Langmuir, 27 (15), 9165-9173 (2011).

15- Guo, L.Y., Yuan, W.Y., Lu, Z.S. and Li, C.M. "Polymer/Nano-Silver Composite Coatings for Antibacterial Applications", Colloids Surf A: Physiochem Eng. Aspects, 439, 69-83 (2013).

16- Yu, W.D., Kuzuya, T., Hirai, S., Tamada, Y. and Sawada, K. "Preparation of Ag Nanoparticle Dispersed Silk Fibroin Compact”, Appl. Surf. Sci., 262, 212-217 (2012).

17- Gorjanc, M., Mozetič, M. and Gorenšek, M. "LowPressure Plasma for Pretreatment of Cotton Fabric for Better Adhesion of Nano-Silver," Tekstilec, 52 (10), 263-269 (2009).

18- Cvelbar, U. and Mozetič, M. "Fundamentals of Oxygen Plasma Physics," Vakuumist, 27 (1-2), 24-33 (2001).
19- Fridman, G., Gutsol, A., Shekhter, A.B., Vasilets, V.N. and Fridman, A. "Applied Plasma Medicine", Plasma Processes and Polymers, 5 (6), 503-533 (2008).

20- Shishoo, R. "Plasma Technologies for Textiles", Wood Head Publishing, Cambridge, UK (2007).

21- Gorjanc, M. and Mozetič, M. "Modification of Fibrous Polymers by Gaseous Plasma", Lambert Academic Publishing, Saarbrücken, Germany (2014).

22- d'Agostino, R. "Plasma Deposition, Treatment and Etching of Polymers", Academic Press, Boston, USA (1990).

23- Cvelbar, U., Mozetič, M. and Klanjšek-Gunde, M. "Selective Oxygen Plasma Etching of Coatings", IEEE Transactions on Plasma Science, 33 (2), 236-237 (2005).

24- Surdu, L., Stelescu, M.D. and Manaila, E. "The Improvement of the Resistance to Candida Albicans and Trichophyton Interdigitale of Some Woven Fabrics Based on Cotton", Bioinorganic Chemistry and Applications, 2014 (1), 1- 16 (2014).

25- Gorjanc, M., Bukošek, V., Gorenšek, M. and Vesel, A. "The Influence of Water Vapor Plasma Treatment on Specific Properties of Bleached and Mercerized Cotton Fabric", Text. Res. J., 80 (6), 557-567 (2010).

26- Gorjanc, M., Bukošek, V., Gorenšek, M. and Mozetič, M. " $\mathrm{CF}_{4}$ Plasma and Silver Functionalized Cotton”, Text. Res. J., 80 (20), 2204-2213 (2010).

27- Gorenšek, M., Gorjanc, M. and Kovač, J. "X-Ray Photoelectron Spectroscopy Characterization of Chemical Changes on PET Knitted Goods Surface after Corona Treatment and Ageing”, Tekstilec, 53 (4-6), 103-112 (2010).

28- Inbakumar, S., Morent, R. and De-Geyter, N. "Chemical and Physical Analysis of Cotton Fabrics Plasma-Treated with a Low Pressure DC Glow Discharge", Cellulose, 17 (2), 417-426 (2010).

29- Ma, P., Huang, J., Cao, G. and Xu, W. "Influence of Temperature on Corona Discharge Treatment of Cotton Fibers", Fibers and Polymers, 11 (6), 941-945 (2010). 
30- Gorjanc, M., Jazbec, K., Šala, M., Zaplotnik, R., Vesel, A. and Mozetič, M. "Creating Cellulose Fibres with Excellent UV Protective Properties Using Moist $\mathrm{CF}_{4}$ Plasma and $\mathrm{ZnO}$ Nanoparticles", Cellulose, 21 (4), 3007-3021 (2014).

31- Jazbec, K., Šala, M., Mozetič, M., Vesel, A. and Gorjanc, M. "Functionalization of Cellulose Fibres with Oxygen Plasma and $\mathrm{ZnO}$ Nanoparticles for Achieving UV Protective Properties", Journal of Nano-materials, 2015, 1-10 (2015).

32- Zhang, D., Chen, L. and Fang, D. "Microwave Assisted Fabrication of Nano $\mathrm{ZnO}$ Assembled Cotton Fibers with Excellent UV Blocking Property and Water-Wash Durability", Text. Res. $J ., 83$ (15), 1625-1633 (2013).

33- Pezelj, E., Tomljenović, A. and Čunko, R. "Textiles for the Protection against Sun Radiation", Tekstil, 53 (6), 301-316 (2004).

34- Sivakumar, A., Murugan, R. and Sundaresan, K. "Certain Investigations on the Effect of Nanometal Oxide Finishes on the Multifunctional Characteristics of Cotton Fabrics", J. Ind. Text., 43 (2), 155-173 (2013).

35- Selvam, S. and Sundrarajan, M. "Functionalization of Cotton Fabric with PVP/ZnO Nanoparticles for Improved Reactive Dyeability and Antibacterial Activity”, Carbohydrate Polymers, 87 (2), 14191424 (2012).

36- Becheri, A., Dürr, M., Nostro, P.Lo. and Baglioni, P. "Synthesis and Characterization of Zinc Oxide Nanoparticles: Application to Textiles as UVAbsorbers", Journal of Nanoparticle Research, 10 (4), 679-689 (2008).

37- Kathirvelu, S., D'Souza, L. and Dhurai, B. "Study of Stain-Eliminating Textiles Using $\mathrm{ZnO}$ Nanoparticles", Journal of the Textile Institute, 101 (6), 520-526 (2010).

38- Karthikeyan, K. and Ramachandran, T. "Effect of Plasma and Chitosan Nanoparticles on Cotton Reactive Dyeing", Journal of Cotton Research and Development, 31 (1), 147-151 (2017).

39- Karthikeyan, K. and Ramachandran, T. "Union Dyeing of Cotton/Nylon Blended Fabric by Plasma-Nano Chitosan Treatment", Fashion and Textiles, 2 (1), 1-10 (2015).
40- Abd Elhady, M.M. "Preparation and Characterization of Chitosan/Zinc Oxide Nanoparticles for Imparting Antimicrobial and UV Protection to Cotton Fabric", International Journal of Carbohydrate Chemistry, 2012 (12), 1-6 (2012).

41- Sricharussin, W., Threepopnatkul, P. and Neamjan, N. "Effect of Various Shapes of Zinc Oxide Nanoparticles on Cotton Fabric for UV-Blocking and Anti-Bacterial Properties", Fibers and Polymers, 12 (8), 1037-1041 (2011).

42- Khalil-Abad, M.S. and Yazdanshenas, M.E. "Bifunctionalization of Cotton Textiles by $\mathrm{ZnO}$ Nanostructures: Antimicrobial Activity and Ultraviolet Protection”, Text. Res. J., 83 (10), 9931004 (2013).

43- Sun, D. and Stylios, G.K. "Investigating the Plasma Modification of Natural Fiber Fabrics-the Effect on Fabric Surface and Mechanical Properties", Text. Res. J., 75 (9), 639-644 (2005).

44-Gorjanc, M., Gorenšek, M., Jovančić, P. and Mozetič, M. "Multifunctional Textiles-Modification by Plasma, Dyeing and Nanoparticles", Chapter 1, Eco-Friendly Textile Dyeing and Finishing, In Tech, Croatia (2013).

45- Yadav, A., Prasad, V. and Kathe, A.A. "Functional Finishing in Cotton Fabrics Using Zinc Oxide Nanoparticles", Bulletin of Materials Science, 29 (6), 641-645 (2006).

46- Lam, Y.L., Kan, C.W. and Yuen, C.W.M. "Effect of Zinc Oxide on Flame Retardant Finishing of Plasma Pre-Treated Cotton Fabric", Cellulose, 18 (1), 151-165 (2011).

47- Lam, Y.L., Kan, C.W. and Yuen, C.W.M. "A Study of Metal Oxide on Antimicrobial Effect of Plasma Pre-Treated Cotton Fabric", Fibers and Polymers, 14 (1), 52-58 (2013).

48- Çakir, B.A., Budama, L., Topel, Ö. and Hoda, N. "Synthesis of ZnO Nanoparticles Using PS-B-PAA Reverse Micelle Cores for UV Protective, SelfCleaning and Antibacterial Textile Applications", Colloids and Surfaces A: Physicochemical and Engineering Aspects, 414, 132-139 (2012). 
49- Vigneshwaran, N., Kumar, S., Kathe, A.A., Varadarajan, P.V. and Prasad, V. "Functional Finishing of Cotton Fabrics Using Zinc Oxide-Soluble Starch Nano-composites", Nanotechnology, 17 (20), 5087-5095 (2006).

50- Kert, M., Jazbec, K., Černe, L., Jerman, I. and Gorjanc, M. "The Influence of Nano-ZnO Application Methods on UV Protective Properties of Cotton," Acta Chimica Slovenica, 61 (3), 587594 (2014).

51- Gorjanc, M. and Gorenšek, M. "Influence of Dyeing Cotton with Reactive Dye on Adsorption of Silver", Tekstilec, 54 (10), 228-237 (2011).

52- Mihailović, D., Šaponjić, Z. and Radoičić, M. "Functionalization of Cotton Fabrics with Corona/ Air RF Plasma and Colloidal $\mathrm{TiO}_{2}$ Nanoparticles", Cellulose, 18 (3), 811-825 (2011).

53- Tsafack, M.J. and Levalois-Grützmacher, J. "Flame Retardancy of Cotton Textiles by PlasmaInduced Graft-Polymerization (PIGP)", Surface and Coatings Technology, 201 (6), 2599-2610 (2006).

54- Palaskar, S.S., Desai, A.N. and Shukla, S.R. "Development of Multifunctional Cotton Fabric Using Atmospheric Pressure Plasma and NanoFinishing”, J. Text. Instit., 107 (3), 405-412 (2016).

55- Kan, C.W., Lam, Y.L. and Yuen, C.W. "Fabric Handle of Plasma-Treated Cotton Fabrics with Flame-Retardant Finishing Catalyzed by Titanium Dioxide", Green Processing and Synthesis, 1 (2), 195-204 (2011).

56- Tang, B., Li, J.L., Hou, X.L., Afrin, T. and Sun, L. "Highly Efficient Dye-Sensitized Solar Cells by Using a Meso-structured Anatase $\mathrm{TiO}_{2}$ Electrode with High Dye Loading Capacity", Ind. Eng. Chem. Res., 52 (12), 4556- 4563 (2013).

57- Phillips, D.M., Drummy, L.F., Conrady, D.G., Fox, D.M. and Naik, R.R. "Dissolution and Regeneration of Bombyx Mori Silk Fibroin Using Ionic Liquids". J Am Chem Soc, 126 (44), 1435014351 (2004).

58- Cai, Z., Jiang, G. and Yangm, S. "Advances in Silk Science and Technology”, Colour Technol., 117 (3), $161-165$ (2001).
59- Gao, Y. and Cranston, R. "Recent Advances in Antimicrobial Treatments of Textiles", Text. Res. $J ., 78$ (1), 60-72 (2008).

60- Kamyar, S., Mansor, B.A., Zin, W.M., Wan, Y. and Abdolhossein, R. "Synthesis of Silver Nanoparticles in Montmorillonite and their Antibacterial Behaviour", Int. J. Nanomedicine, 6, 581-590 (2011).

61- Rani, K.V., Sarma, B. and Sarma, A. "Plasma Pretreatment on Tasar Silk Fabrics Coated with ZnO Nanoparticles against Antibacterial Activity", Surface Review and Letters, 26 (5), 1-11 (2019).

62- Intarasang, W., Thamjaree, W., Boonyawan, D. and Nhuapeng, W. "Effect of Coating Time on LPP Treated Silk Fabric Coated with ZnO Nanoparticles”, Chiang Mai Journal of Science, 40 (6), 1000-1005 (2013).

63- Yu, W.H., Zhang, Y., Kang, E.T., Neoh, K.G., $\mathrm{Wu}$, S.Y. and Chow, Y.F.J. "Electroless Plating of Copper via a Sn-Free Process on Dielectric SiLK Surface Modified by UV-Induced Graft Copolymerization with 4-Vinylpyridine and 1-Vinylimidazole", Electrochem. Soc., 149 (10), C521-C528 (2002).

64- Şahan, G. and Demir, A. "A Green Application of Nano Sized Chitosan in Textile Finishing", Tekstil Ve Konfeksiyon, 26 (4), 414-420 (2016).

65- Vílchez, S., Manich, A.M., Jovancic, P. and Erra, P. "Chitosan Contribution on Wool Treatments with Enzyme", Carbohydrate Polymers, 71 (4), 515-523 (2008).

66- Kotlińska, A. and Lipp-Symonowicz, B. "Research on the Enzymatic Treatment of Wool Fibres and Changes in Selected Properties of Wool", Fibres \&Textiles in Eastern Europe, 19 (3), 88-93 (2011).

67- Pakdel, E., Daoud, W.A., Sun, L. and Wang, X. "Photo-stability of Wool Fabrics Coated with Pure and Modified $\mathrm{TiO}_{2}$ Colloids", Journal of Colloid and Inter face Science, 440, 299-309 (2015).

68- Demir, A., Ozdogan, E. and Ozdil, N. "Ecological Materials and Methods in the Textile Industry: Atmospheric-Plasma Treatments of Naturally Colored Cotton", J. Appl. Polym. Sci., 119 (3), 1410-1416 (2011). 
69- Biniaś, D., Włochowicz, A. and Biniaś, W. “Selected Properties of Wool Treated by Low-Temperature Plasma", Fibres and Textiles in Eastern Europe, 12 (2), 58-62 (2004).

70- Hegemann, D., Hossain, M.M. and Balazs, D.J. "Nanostructured Plasma Coatings to Obtain Multifunctional Textile Surfaces", Progress in Organic Coatings, 58 (2-3), 237-240 (2007).

71- Zhang, H. and Wang, L.L. "Study on the Properties of Woolen Fabric Treated with Chitosan/ $/ \mathrm{TiO}_{2}$ Sol", J. Text. Inst., 101 (9), 842-848 (2010).

72- Onar, N. and Sarışı1k, M. “Application of Enzymes and Chitosan Biopolymer to The Anti- felting Finishing Process", J. Appl. Polym. Sci., 93 (6), 2903-2908 (2004).

73- Lewis, D.M. "The Structure of Wool", Wool Dyeing, Soc. of Dyers and Colour., Bradford (UK), 2-3 (1992).

74- Huang, K., Sheu, Y. and Chao, I. "Preparation and Properties of Nano-chitosan", Polymer-Plastics Technol. and Eng., 48 (12), 1239-1243 (2009).

75- Yang, H., Wang, W. and Huang, K. "Preparation and Application of Nano-chitosan to Finishing Treatment with Anti-Microbial and Anti-Shrinking Properties", Carbohydrate Polymers, 79 (1), 176179 (2010).

76- Ali, S.W., Rajendran, S. and Joshi, M. "Synthesis and Characterization of Chitosan and Silver Loaded Chitosan Nanoparticles for Bioactive Polyester", Carbohydrate Polymers, 83 (2), 438446 (2011).

77- Gouda, M. and Hebeish, A. "Preparation and Evaluation of $\mathrm{CuO} /$ Chitosan Nano-composite for Antibacterial Finishing Cotton Fabric", J. Ind. Text., 39 (3), 203-214 (2010).

78-Hebeish, A., Sharaf, S. and Farouk, A. "Utilization of Chitosan Nanoparticles as a Green Finish in Multifunctionalization of Cotton Textile", International Journal of Biological Macromolecules, 60, 10- 17 (2013).

79- Kaliyamoorthi, K. and Thangavelu, R. "Union Dyeing of Cotton/Nylon Blended Fabric by Plasma-Nano Chitosan Treatment", Fashion and Textiles, 2 (1) 1-10 (2015).

J. Text. Color. Polym. Sci. Vol. 17, No.2 (2020)
80- Balazs, D.J., Triandafillu, K., Wood, P., Chevolot, Y., Delden, C., Harms, H., Hollenstein, C. and Mathieu, H.J. 'Inhibition of Bacterial Adhesion on PVC Endotracheal Tubes by RF-Oxygen Glow Discharge, Sodium Hydroxide and Silver Nitrate Treatments', Biomaterial, 25 (11) 2139-2151 (2004).

81- Davies, R.L. and Etris, S.F. 'The Development and Functions of Silver in Water Purification and Disease Control', Catalysis Today, 36 (1), 107114 (1997).

82- Fox, C.L., Rappole, B.W. and Stanford, W. "Control of Pseudomonas Infection in Burns by Silver Sulfadiazine," Surgery, Gynecology and Obstetrics, 128 (5), 1021-1026 (1969).

83- Favia, P., Vulpio, M., Marino, R., d'Agostino, R., Mota, R.P. and Catalano, M. "Plasma Deposition of Ag-Containing Polyethyleneoxide-like Coatings", Plasmas Polym, 5 (1), 1-14 (2000).

84- Balazs, D.J., Triandafillu, K., Sardella, E., Iacoviello, G., Favia, P., d'Agostino, R., Harms, H. and Mathieu, H.J. "PE-CVD Modification of Medical Grade PVC to Inhibit Bacterial Adhesion: PEO-like and Nano-Composite Ag/PEO-like Coatings", In: R. d'Agostino, P. Favia, M. R. Wertheimer and C. Oehr, Eds., Plasma Processes and Polymers, Wiley-VCH, Verlag GmbH \& Co. KGaA, Weinheim, pp.351-372 (2005).

85- Balazs, D.J., Hollenstein, C. and Mathieu, H.J. "Fluoropolymer Coating of Medical Grade Poly (Vinyl Chloride) by Plasma-Enhanced Chemical Vapor Deposition Techniques", Plasma Process Polym, 2 (2), 104-111 (2005).

86- Lopez, G.P., Ratner, B.D., Tidwell, C.D., Haycox, C.L., Rapoza, R.J. and Horbett, T.A. "Glow Discharge Plasma Deposition of Tetraethylene Glycol Dimethyl Ether for Fouling-Resistant Biomaterial Surfaces", J Biomed Materials Res, 26 (4), 415-439 (1992).

87- Allam, O.G. "Improving Functional Characteristics of Wool and Some Synthetic Fibres", Open Journal of Organic Polymer Materials, 3, 8-19 (2011).

88-Montazer, M. and Seifollahzadeh, S. "Pre-Treatment of Wool/Polyester Blended Fabrics to Enhance Titanium Dioxide Nanoparticle Adsorption and Self-Cleaning Properties", Color Technol, 127 (5), 322-327 (2011). 
89- Seifolahzadeh, S. and Montazer, M. "Self-Cleaning of Methylene Blue and Acid Blue 113 on Wool/ Polyester Fabric Treated with Nano Titanium Oxide Under UV Irradiation without Yellowing”, $J$ Color Sci. Technol., 4 (1), 115-123 (2010).

90- Aminoddin, H., Ahmad, M.S., Firoozmehr, M. and Sayyedeh, E.T. "Environmentally Friendly Pretreatment for Enhanced Coating of $\mathrm{TiO}_{2}$ Nanoparticles on PET/Wool Fabric", Inter. Conf. on Chemical, Civil and Environmental Engineering, Singapore 18-19 Nov (2014).

91- Kotlińska, A. and Lipp-Symonowicz, B. "Research on the Enzymatic Treatment of Wool Fibres and Changes in Selected Properties of Wool", Fibres \& Textiles in Eastern Europe, 19 (3) 88-93 (2011).

92- Kang, J.Y. and Sarmadi, M. "Textile Plasma Treatment Review - Natural Polymer-Based Textiles”, AATCC Review, 4 (10), 28-32 (2004).

93- Gorjanc, M., Recelj, P. and Gorenšek, M. "Plasma Technology for Textile Purposes", Tekstilec, 50 (10-12), 262-266 (2007).

94- Perepelkin, K.E. "Principles and Methods of Modification of Fibers and Fiber Materials", Fiber Chem., 37 (2), 123-140 (2005).

95- Perepelkin, K.E. "Trends and Changes in World Chemical Fiber Production”, Fiber Chem., 35 (3), 241-249 (2003)

96- Coyle, S., Wu, Y., Lau, K., De Rossi, D., Wallace, G. and Diamond, D. "Smart Nano Textiles: A Review of Materials and Applications", MRS Bull, 32 (5), 434-442 (2007).

97- Da Rocha, A. "Development of Textile-Based High-Tech Products: The New Challenge", Studies in Health Technology and Informatics, 108, 330334 (2005).

98- Tang, S.L.P. and Stylios, G.K. "An Overview of Smart Technologies for Clothing Design and Engineering”, Int. J. Cloth Sci. Technol., 18 (2), 108-128 (2006).

99- Rivero, P.J., Urrutia, A., Goicoechea, J. and Arregui, F.J. "Nano-materials for Functional Textiles and Fibers", Nano-scale Research Letter, $10(0.1), 1-22$ (2015)

100- https://sewport.com/fabrics-directory/polyamidefabric

101- https://en.wikipedia.org/wiki/Polyester
102- Carlotti, S. and Mas, A. "Improvement of Adhesion of PET Fibers to Rubber by ArgonOxygen Plasma Treatment", J. Appl. Polymer Sci., 69 (12), 2321- 2330 (1998).

103- Chen, J.R., Wang, X.Y., and Tomiji, W. "Wettability of Poly (ethylene terephthalate) Film Treated with Low-Temperature Plasma and their Surface Analysis by ESCA", J. Appl. Polymer Sci., 72 (10), 1327- 1333 (1999).

104- Inagaki, N., Tasaka, S. and Shimada, S. "Comparative Studies on Surface Modification of Poly (ethylene terephthalate) by Remote and Direct Argon Plasmas", J. Appl. Polymer Sci., 79 (5), 808-815 (2001).

105-Bozzi, A., Yuranova, T. and Kiwi, J. "Self-Cleaning of Wool-Polyamide and Polyester Textiles by $\mathrm{TiO}_{2}-$ Rutile Modification under Daylight Irradiation at Ambient Temperature", J. Photochem. Photobiol. A: Chem., 172 (1), 27-34 (2005).

106- Daoud, W.A., Xin, J.H. and Zhang, Y.H. "Surface Functionalization of Cellulose Fibers with Titanium Dioxide Nanoparticles and their Combined Bactericidal Activities", Surf. Sci., 599 (1-3), 69-75 (2005).

107- Qi, K.H., Daoud, W.A., Xin, J.H., Mak, C.L., Tang, W.S. and Cheung, W.P. "Self-Cleaning Cotton”, J. Mater. Chem., 16, 4567-4574 (2006).

108- Hossain, M.M., Herrmann, A.S. and Hgemann, D. "Plasma Hydrophilisation Effect on Different Textile Structures. Plasma Process", Polym., 3 (3), 299-307 (2006).

109- Hesse, A., Hocker, H., Umbach, K.H. and Mecheels, J. "Surface Modification of Wool and Polyester Knitwear in Relation to Wear Comfort", Proceedings of the Harrogate Meeting, Harrogate, Great Britain, IWTO, Report no. 12 (1995).

110- Wakida, T. and Tokino, S. "Surface Modification of Fiber and Polymeric Materials by Discharge Treatment and Its Application to Textile Processing”, Indian J. Fiber. Text., 21 (1) 69-78 (1996).

111- McCord, M.G., Hwang, Y.J., Hauser, P.J., Qiu, Y., Cuomo, J.J., Hankins, O.E., Bourham, M.A. and Canup, L.K. "Modifying Nylon and Polypropylene Fabrics with Atmospheric Pressure Plasmas", Textile Res. J, 72 (6), 491-498 (2002). 
112- Raffaele-Addamo, A., Riccardi, C., Selli, E., Barni, R., Piselli, M., Poletti, G., Orsini, F., Marcandalli, B., Massafra, M.R. and Meda, L. "Characterization of Plasma Processing for Polymers", Surf. Coat. Technol., 174-175, 886-890 (2003).

113- Wu, D. and Fang, Y. "The Adsorption Behavior of p-Hydroxy benzoic Acid on a Silver Coated Filter Paper by Surface Enhanced Raman Scattering", Colloid Int. Sci., 265 (2), 234-238 (2003).

114- Badr, Y. and Mahmoud, M.A. "Size-Dependent Surface-Enhanced Raman Scattering of Sodium Benzoate on Silver Nanoparticles", J. Mol. Struct., 749 (1-3), 187-192 (2005).

115- Damm, C., Munstedt, H. and Rosch, A. "LongTerm Antimicrobial Polyamide 6 / SilverNanocomposites", J. Mater. Sci., 42, 6067-6073 (2007).

116- Jiang, S.Q., Yuen, C.W.M., Tao, X.M., Kan, C.W. and Choi, P.S.R. "Low Temperature Plasma Pretreatment of Polyester Fabric for Chemical Silver Plating", $6^{\text {th }}$ AUTEX Conference, Raleigh NC, USA, 1-7 Jun (2006).

117- Krstulović, N., "Plasma Assisted Modification of Cellulosic Substrate Properties and Nanoparticles Impregnation”, Materials, 11 (12), 2412-2423 (2018). 


\title{
التطورات الحديثة في علاج الياف النسيج بالبلازما / الجسيمات النانوية

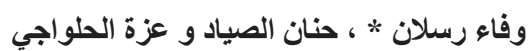 شعبة بحوث الصناعات النسيجية ، المركز القومي للبحوث ، القاهرة 12622 ، مصر
}

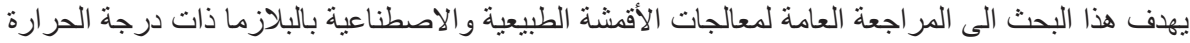

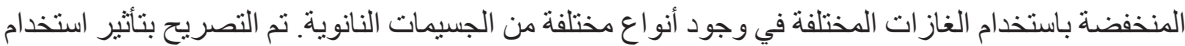

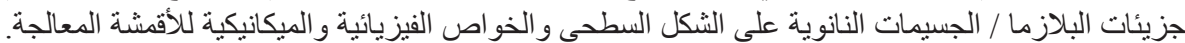

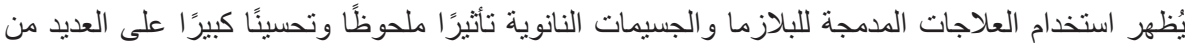

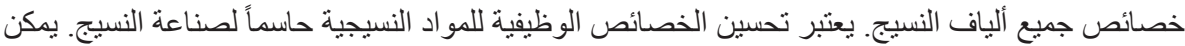

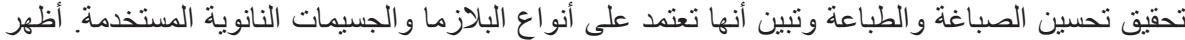

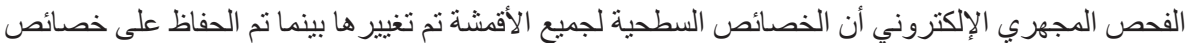

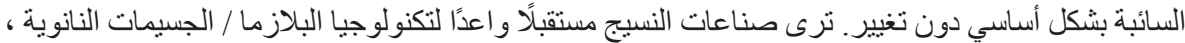
مع فو ائد الحفاظ على البيئة والطاقة ، في تطوير مو اد عالية الأداء لللسوق العالمية.
\end{abstract}

